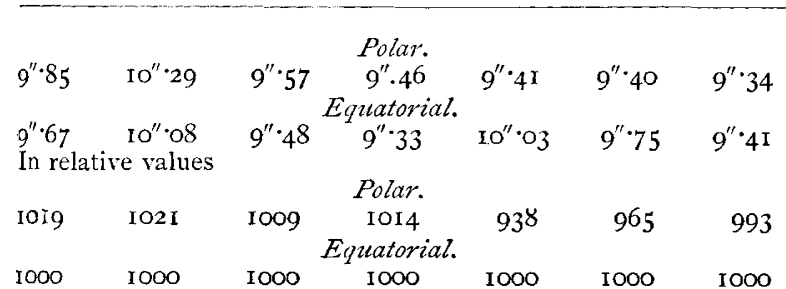

At first sight it would seem that the later August measures do not support the rule. Closer consideration will, however, show that they do. For while in July the polar cap was still large, and in consequence reached to the limb, even when its centre was at some distance from it, by August it had dwindled to so small a patch as to be incapable of doing so when at the same angular distance away. Taking account of this fact, it will be seen that the effect is quite in accordance with the position, as comes out clearly in the relative values for the two diameters of August 14 and August 2 I.

It will now be evident why so large, and intrinsically so un. mistakable, an effect as that of the Martian twilight should hitherto have escaped detection; the reason being that the twilight effect and the irradiation from the polar cap each increased their respective diameters to a simultaneous augmentation of both, conspiring each thus to mask the other.

Had measures been continued through a series of months, and been made in sufficient number, both causes must have made themselves evident. For both are periodic, and their periods are not the same. The irradiation from the polar cap has a primary period of thirty-seven days, a secondary one of a Martian year as well as a third depending on the tilt of the pole toward the earth; that of the twilight fringe a varying one of about thirteen months. But as previous measures have been made quite regardless of the twilight effect, and largely regardless of the polar cap, regardless, that is, of its varying position; the results have merely disagreed with each other, and the disagreements been credited to errors of observation. One result of this was discordance in the value of the polar flattening.

When we take both causes into account we find that the means of the July and August observations confirm the October and November ones.

For by comparing the values of the polar diameter when on and away from the limb, it is possible to deduce both the amount of the irradiation from the polar cap and the value of the twilight band from the measures themselves. The results in the case of Mr. Douglass agree with those of his OctoberNovember measures. In the case of Prof. Pickering, there is the same relative difference between the determinations, although the absolute values are all smaller.

That in the table the corrections to the July and August measures differ from those applied to the later ones, comes from the different manner of their taking; in the July and August measures the longitudinal thread of the micrometer having been set to the phase axis or perpendicular to it, instead of to the polar one.

In Mr. Douglass' determinations the value for the twilight arc comes out $8^{\circ}$. This is somewhat smaller than the result from the November measures. But a smaller value is precisely what should have been found. For the greater the phase angle, the less the foreshortening, which foreshortening by massing the illumination lets the fringe of light become evident farther out. Now the average phase angle was $43^{\circ}$ in July and August, as against $18 \frac{1}{2}^{\circ}$ in November.

From Prof. Pickering's measures the twilight arc comes out greater, or I $I^{\circ}$, and by inference would have come out greater still in November.

Thus it appears that measures made by separate observers, and measures made before and after opposition, all confirm each other to the existence of a twilight band upon the planet.

$$
\text { Percival Lowei, } 1 .
$$

\section{THE FOUNDATIONS OF ENGINEERING} EDUCATION. ${ }^{1}$

I ET us consider what is the education which a young man needs to fit him for the profession of engineering, whatever be the special line of engineering which he proposes to follow. 1 Extracted from a course of lectures delivered in the Lowell Institute, Boston, by Prof. G. Lanza, Professor of Theoretical and Applied Mechanics, Massachusetts Institute of Technology, and published in the Joumal of the Franklin Institute.

$$
\text { NO. I } 347 \text {, VOL. } 52 \text { ] }
$$

And, before discussing the details of what he ought to study, let us consider what it is that we desire to accomplish by giving him an engineering education. Naturally, we wish, as far as any education can accomplish it, to put him in the best condition to meet and grapple with the duties, the problems, and the responsibilities of his profession, as they arise.

There are two things which are absolutely necessary to make a successful engineer : first, a knowledge of scientific principles and of the experience of the past ; and second, his own experience. The last cannot be given in a school, and each one must gain it for himself in his practice.

But the greater his familiarity with scientific principles and the experience of the past, the more able will he be to advance in his profession, and to be trusted to assume responsibility; in. deed, if a man is ignorant of certain details and knows he is ignorant, he can-and if he is the right kind of a man, he willtake pains to learn them, if they bear on the work he has in hand; but if he is ignorant of scientific principles, it is very likely that he does not know he is ignorant, or, if by good luck he becomes aware of the fact, it is next to impossible for him to devote the time and study necessary to correct his ignorance while his mind is busy with his daily work.

Moreover, a man who is not familiar with the scientific principles which concern his work is not a safe man to trust with responsibility; for scientific principles are merely the laws of nature, as far as known, as shown by the experience of the past.

Hence it is that the first and most important thing to be done for the student is to give him a thorough drill in the scientific principles which find their application in his profession. It is in the school that this knowledge may best be acquired, since it is only with great difficulty that principles can be mastered after the student begins practice, and then as a rule but very imperfectly; and this view is borne out by those engineers who have been successful, and who have had to acquire their knowledge of scientific principles little by little, and as best they could, during the practice of their profession. Too much cannot be said by way of insisting that a thorough mastery of such scientific principles far outweighs in importance anything else that can be done for the student; and this is so true, that it is a decided mistake to neglect it in order to impart to him greater skill in such processes as will probably engage his attention the first year after he goes to work, as, for instance, to make him a skilful surveyor, a finished machinist, or an elegant draughtsman. Greater skill can far more easily be acquired after he goes to work than can scientific principles, and if this mistake is made the consequences will probably pursue him throughout his professional life.

The two fundamental sciences upon which the scientific principles of engineering are especially dependent are mathematics and physics, and no proper course in engineering can be arranged without insisting upon these fundamentals.

Let us begin with the subject of pure mathematics, and consider what portions should be studied, how they should be studied, or rather how they should be known, and of what service they are to the engineer after they have been mastered; bearing in mind that, in accordance with the opinions already expressed, the course of study should be laid out with direct reference to the needs of the engineer; and that when it is so laid out, it will, by the very fact that it leads to a definite end, subserve best the purpose of true education, and hence of developing the powers of the mind. Probably the best definition of mathematics is that given by Prof. Benjamin Pierce, who This definition, of course, includes formal logic, and hence embraces more than is ordinarily understood by mathematics. We may assert, however, that the only function of mathematics is to draw necessary conclusions from the assumed data. Mathematics has nothing whatever to do with the correctness or incorrectness of the data. If these are correct, the conclusions deduced by mathematics will also be correct; whereas, if the data are false, the conclusions deduced by mathematics will be false.

Thus, if we require the sum o. a certain set of numbers, the process of addition will give the correct result, provided the numbers added are the right ones; but if the numbers added are not the right ones, the result of the addition will not be the one desired. Indeed, we might compare pure mathematics to a mill -it will only produce good meal when the corn furnished to it to grind is of good quality; and if the corn is poor, the meal pro- 
duced will be poor. With the selection of the corn which it is to grind, the mill has nothing to do.

No natural law can be discovered or proved by mathematics alone ; the discovery or proof of natural law requires experiment and observation in all cases.

Just as arithmetic is a means of making calculations of certain kinds, so there are other kinds of calculations that can only be performed by the use of mathematics higher than arithmetic; some kinds require algebra, some geometry, some trigonometry, some descriptive geometry, some analytic geometry, and some the differential and integral calculus; while others yet require higher mathematics. Now, inasmuch as every one can easily understand the necessity of arithmetic for the purpose of making the calculations, and drawing the conclusions which come within its province; so, it follows that the engineer should have a thorough working knowledge of whatever portions of pure mathematics he needs, to make the calculations that are liable to arise in his work, and also to draw the necessary conclusions which concern the engineering and scientific subjects with which he must deal in his profession. This latter is an allimportant matter; for, if our prospective engineer is to be fit to assume responsibility at some portion of his career, before he allows himself to use a formula in practice, he ought to know just how it is deduced, and what are the assumptions that were made in deducing it.

The rule-of-thumb engineer ignores this matter, and allows himself to risk the money, the safety, and the lives of his fellow men by making use of constants and mathematical formulæ found in some hand-book or elsewhere ; using these constants and formulæ blindly, without knowing how they were deduced, or whether they have any reasonable foundation to stand on ; or, in other cases, contents himself with merely guessing at what should be the dimensions of the various parts of a structure or machine. The natural result of such a course is poor work, and often disaster ; and the world is rapidly waking up to this fact, so that important engineering work is being less and less entrusted to these rule-of-thumb engineers.

Now, I may say that knowledge of at least all these subjects mentioned in my communication-through the differential and integral calculus-is necessary for our prospective engineer.

As to descriptive geometry, that is classed by many, not as mathematics, but as a branch of drawing. It is the mathematical work upon which the making of engineering drawings of all sorts is based, and hence I have put it in this list.

So general has the conviction become that the engineer needs some knowledge of the differential and integral calculus, that it is not necessary for me to cite cases where he must use it if he is to perform his work intelligently and not by rule-of-thumb. Differential equations is a subject which is sometimes classed with the differential and integral calculus, and sometimes as a separate subject. It is one that should, if possible, be learned at least to a small extent, though the more that is known about it the better.

As to the special work to be cione in each of these subjects, it is a matter of judgment with the one who lays out the course, and I shall not weary you with these details; but I must explain what ought to be the result aimed at, in other words, how the student should know his mathematics.

I might express my idea by saying that he should acquire the ability to use it as a tool, but, when I say that, I mean not merely as a tool for making computations, but also as a tool for drawing necessary conclusions of the kinds that apply to his engineering work; and this last is the feature which is most frequently lacking in the mathematical instruction given to engineering students.

By one method often pursued in teaching mathematics, the student is made to grind through a certain round of operations over and over until he has been so drilled in performing them mechanically that he can perform a similar problem. By this method, he is only taught to use it as a tool for making computations.

Another method, often pursued, is to exercise the student's ingenuity in performing a variety of (sometimes puzzling) problems which are of purely abstract interest, and are not planned in such a way as to bear upon the class of problems liable to arise in engineering work or study. This course probably tends to make the student do more thinking, but does not direct his thinking in the channel most useful for the prospective engineer. To accomplish the desired object in the teaching of mathematics, it is, of course, necessary that the teacher should be able to grasp the requirements of the engineering courses, and should know the special kind of use that the prospective engineer will have for his mathematics in later life.

Another important matter, the accomplishment of which concerns the treatment of the subjects of a mathematical nature that follow in his course, rather than the treatment of the pure mathematics itself (though the mathematical department can help in this matter), is that the student should be taught to distinguish between the mathematics of the work, and the assumptions made at the beginning, or in the course of it, respecting the proposition he is dealing with.

Perhaps I might sum up a part of the foregoing by saying that the student should be taught to think, and that the attempt to teach him to think should begin as early as possible in his course, and be kept up throughout. It is much easier for the average student to learn a lesson to recite by rote even if it contains a lot of formulæ, than it is to do a little solid thinking himself, and yet the more we can make him think the more successful in every way will he be.

Perhaps those of you (if there be any) who teach mathematics may think that the standard I have set is high. I admit that it is, and also that it requires hard work, good judgment, and the qualities of a good and efficient teacher, not only in laying out the course, but even more in teaching the class. Nevertheless, this standard is the one that is needed, and good judgment, and good teaching can at least approach near to it within the time that can be afforded in our engineering courses, even with such previous mathematical preparations as can be obtained to-day by the students before they enter the engineering schools; and as fast as it becomes possible to raise the standards of admission, the standard I have set can be even more fully realised.

The other fundamental science which I have mentioned is physics. It may be defined as that department of natural science which treats of the laws governing the various manifestations of energy (as gravitation, sound, heat, light, electricity, \&c.).

It deals with the natural law as it applies to just those classes of bodies, and substances with which the engineer does his work. Indeed, physics is a very general term, and might be made to include a great many subjects that are ustally called by some more special name. For instance, mechanics is sometimes spoken of as a separate science, and sometimes as forming a part of physics, and, moreover, under any definition physics includes a part of mechanics.

Practically, a course in physics is the suitable preparation for a proper understanding of the scientific principles of most of the engineering work with which the student will come in contact. Treating, as it does, of the laws of nature, the more thoroughly an engineer knows it, the more successful will he be, and an ignorance of these laws can only result in failure.

Mechanics, light, sound, heat, and electricity, are all matters that concern the profession of the engineer so intimately that he cannot afford to neglect a careful study of their first principles. It is unnecessary for me to say, therefore, that there is no portion of the work usually treated in the best and most thorough courses of general physics but what should be included in the course of our prospective engineer.

Then, a certain amount of work in the physical laboratory is of great importance for the student, for it teaches him how to ask questions of nature, and how to get correct answers ; in other words, how to make careful and accurate experiments, and this is a matter that intimately concerns the engineer. It is true that the greater part of his experimental work will have to be performed on a considerably larger scale than that usually carried on in a physical laboratory; but, on the other hand, some of his most important and delicate work involves the doing of just such experimental work as he is taught to carry on in a well-organised and well-equipped physical laboratory ; and also the performance of these physical laboratory experiments is a proper introduction to his later course of experiments on the large scale, drilling him in accuracy and care while working on small amounts of material.

Indeed, I might mention quite a number of experiments which are all-important to the engineer, and in regard to which, it would be difficult to decide whether they should be called physical laboratory or engineering laboratory experiments, since they often have to be performed in both. Thus, the calibration of thermometers is a matter that is properly taught in the former, and yet the engineer who is to do delicate engineering work is liable to have to calibrate his thermometers, or at least to make a careful and accurate comparison with a standard which he or

NO. I 347 , VOL. 52] 
some one else has calibrated. Again, the determination of the mechanical equivalent of heat is a matter of vital importance to the engineer, but the best and most accurate work thus far upon the subject has been done by Prof. Rowland, a physicist, in his physical laboratory.

As a rule, when experiments are to be performed on the large scale they get beyond the possibilities of a physical laboratory. In this category we may place such experimental work as the testing of steam engines and steam boilers, the testing of the strength of materials of construction on a practical scale, \&c. ; but, in order to carry out these tests with proper accuracy, we have generally to perform delicate measurements, as, for instance, measurements of temperatures, \&c., in the first, and measurements of very small elongations or shortenings in the second case, and consequently have to use the suitable apparatus with the necessary degree of accuracy.

Since we have just been considering mathematics and physics, which may be called general sciences, perhaps a few words should be said in regard to chemistry. I cannot claim for it a similar position of fundamental importance in the engineering part of an engineering course that belongs to mathematics and physics. Nevertheless, a certain amount of chemical knowledge is of great importance to all engineers; but when they have passed this point, although a farther knowledge would be useful, it is not one of the most important things. The chemical composition of fuels, of steels and irons, of cements, of oils, and of other materials, is a matter that directly concerns the engineer. It is true that he can usually have his chemical analyses made for him, and generally would better do so; but he must know enough of chemistry to understand the bearing which the chem. ical composition of his materials have on their use in engineering work. Some knowledge of industrial chemistry is also desirable, so that be shall understand the nature of the processes performed in manufactories in which chemical processes on a large scale are performed.

The instruction in chemistry should, if possible, be given very early in the student's course. In the case of the Massachusetts Institute of Technology, and also, I think, in that of several other schools, both lectures and laboratory work in chemistry are given in the first year, and when this is done the instruction in chemistry fulfils another important function, viz. it introduces the student at the very threshold of his course to a species of scientific work that obliges him to think, and this, in a direction in which, as a rule, he has not been trained in the preparatory schools. Especially is this true of the laboratory work, for, by observing the results of experiments which he himself makes, he must learn how to interpret the replies of nature; and as chemistry, unlike mathematics, is an experimental science, it trains the thinking powers of the student even more than do his algebra, geometry, and trigonometry.

\section{UNIVERSITY AND EDUCATIONAL INTELLIGENCE.}

A PROSPECTUS of the course in practical chemistry at the Polytechnic Institute of Brooklyn has been received, and it indicates that very efficient work is carried on at the Polytechnic. The course, which is under the direction of Prof. P. T. Austen, appears to be adapted in every way to meet the wants of the day, and to train competent analytical and technical chemists. The claims of pure chemistry are also recognised, facilities being given for post-graduate work in it, as well as in applied chemistry and chemical engineering.

THE Department of Science and Art has issued the following lists of Scholarships and Exhibitions just awarded :- Whitworth Scholarships (tenable for three years), $\mathbf{I}_{25}$ a year each : Arthur H. Barker (24), engineer; George W. Shearer (2I), apprentice engineer ; Percy Nicholls (24), engineer; Harold R. Cullen (21), engineer. Whitworth Exhibitions. (tenable for one year), $£ 50$ a year: Charles $E$. Goodyear (2I), shipwright ; George $M$. Brown (23), draughtsman; Norton Baron (22), engineering student; Harry Jackson (20), engineering student: Edward M. Leflufy (22), engine-fitter apprentice; Arthur E. Hyne (21), fitter apprentice ; Robert McMillan (20), engineer apprentice; John W. Roebuck (23), fitter; George Follows (24), engineer Arthur J. Baker (19), engine-fitter apprentice; William D. Ross (2I), fitter ; Frank H. Phillips (20), engineer apprentice ; Henry T. Hildage (20), fitter; William.P. Jones.(25), marine engineer; John W. Milner (20), mechanical engineer; William Bayliss (20), apprentice. fitter; John B. Shaw (2I), engineer; Tames
Walker (22), engineer; William H. C. Kemp (2I), engineer apprentice ; William J. Talbot (23), engineer ; Henry C. Trigg (24), draughtsman; Duncan R. McLachlan (24), engineer ; George A. Robertson (2I), engineering student; Charles $H$. Imrie (22), engineer; William McG. Wallace (20), apprentice fitter ; William J. Gow (20), apprentice fitter; William Lauder (20), draughtsman; Samuel A. Clarke (25), draughtsman; Edmund B. Ball (2I), engineer student; Jabez W. Ashdown (20), engineer apprentice.

THE list of successful candidates for Royal Exhibitions, National Scholarships, and Free Studentships (Science) is as follows :-National Scholarships for Mechanics: Edmund R. Verity ( I 9), student ; George Patchin (17), engineering student; Harry Jackson (20), engineering student; William Ditchburn, jun. (I9), teacher. National Scholarships for Chemistry and Physics: Thomas S. Price (19), student; Franz E. Studt (2r), tailor; Herbert Bailey (I8), student ; William Bennett (16), student ; John W. Barker (18), laboratory assistant. National Scholarships for Biological Subjects: Thomas G. Hill (r9), student ; Ernest A. Scott (I7), student. National Scholarships: Charles E. Croodyear (2I), shipwright ; Edward M. Leflufy (22), engine-fitter apprentice; William $\mathrm{H}$. James (22), student; William T. Clough (I8), student; Herbert Halliday (22), student ; William Cameron (18), laboratory assistant ; Ernest Hibbert (15), student; Sidney E. Lamb (21), engine-fitter apprentice; Joseph Lister (I9), teacher; William Parker (19), student ; Ernest T. Harrison (I8), laboratory assistant. Royal Exhibitions : George E. Clarke ( I 7), student ; Edward C. Hugon (I6), student ; Thomas G. Procter (I9), engine-fitter apprentice ; John A. Tomkins (20), scientific instrument maker ; William T. Swinger (20), engineer; John W. Roebuck (23), fitter ; Robert L. Wills (2r), shipwright apprentice. Free Studentships : William D. Ross (2I), fitter ; Leonard W. Cox (2r), student ; Edgar R. Sutcliffe (20), engineer ; William P. Jones (25), marine engineer ; Percy M. Hampshire (19), lecture assistant; William $\mathrm{J}$. Talbot (23), engineer.

\section{SCIENTIFIC SERIALS.}

Bulletin de l'Academie des Sciences de St. Petersbourg, 5th series, t. ii. No. 4, April I 895.-Proceedings, in which we notice the discovery, by G. Schneider, in Prof. Kovalevsky's laboratory, of lymphatic glands in the earth-worm, Dendrolana rubida (Crimea), and in Perichata; as well as a communication by $\mathrm{E}$. Burinsky, on his method of restoring by means of photography the writing in old documents which time has rendered invisible. A number of good negatives having been taken on collodion pellicules, they are superposed, and the visibility of the faintest markings is rendered still greater by means of a "contrast positive" obtained with regulated artificial light.-Definitive researches into the variations of latitude at Pulkova, on the ground of older observations made with the great vertical circle, by A. Ivanoff (in French). The previous memoirs of the author on the same subject being considered as first approximations only, the definitive formulæ are now given. The observations of the years I863-1875 and I $842-1849$ are treated for that purpose separately. Both series lead to formulæ which agree very well with the formula given by Mr. Chandler in the Astronomical Journal, No. 322; however, the Pulkova observations of the first-named period seem to point to the necessity of slightly reducing the half-amplitude of the yearly term in Chandler's formula. Two long series of Pulkova observations thus fully confirm Mr. Chandler's conclusions.--On the measurements and calculations of some photographic charts of the stars, by F. Renz (in German). A catalogue of all stars, down to the magnitude $\mathrm{II}^{\circ} \mathrm{O}$, which were occultated by the moon during the last eclipse, was given in the Astronomische Nachrichten. It appeared, however, that occultations of stars down to the twelfth magnitude could be observed at several observatories. Accordingly, the corresponding region of the sky was photographed by Prof. Donner with such an exposure (25 minutes) as to obtain the stars of twelfth magnitude as well, and $F$. Renz measured their positions with the Pulkova Repsold apparatus. The Potsdam photographs of the same region, made in 1891 , were also re-measured, while the right ascensions of thirty-five fundamental stars were accurately determined at Pulkova with the meridian circle. The agreement between the different plates is quite satisfactory; and no distortion of the field could be detected. However, there are certain small systematic errors which cannot yet be well

NO. I 347 , VOL. 52 ] 